\title{
Between-herd movements of cattle as a tool for evaluating the risk of introducing infected animals
}

\author{
Pauline EZANNO*, Christine Fourichon, François BEAUdEAU, \\ Henri SEEGERS
}

Unit of Animal Health Management, Veterinary School \& INRA, BP 40706, 44307 Nantes Cedex 03, France

(Received 25 February 2005 - Accepted 31 January 2006)

\begin{abstract}
The spread of pathogens between cattle herds is closely related to the between-herd contact structure. This structure is based on neighbourhood relationships, animal movements and other infectious contacts. The aim of this study was to qualify and quantify cattle movements between herds and their heterogeneity in order to evaluate the theoretical risk of introducing infected animals in herds. Data collected from 1998 to 2002 were studied for every cattle herd located in Brittany. Herd-year types were based on herd size, cow numbers per breed, and fattening units (veal-calf, bull fattening). Herd-years were either isolated (no introduction, no transfer to another herd), closed source (no introduction, at least one transfer), open source (introduction and transfer) or strictly destination (introduction but no transfer) herds. A third of the herds were open source and $16 \%$ were isolated. The proportions varied with the herd-year type and the fattening unit. Open herds had almost as many source herds as yearly introduced animals. The contact structure between cattle herds was complex and heterogeneous. Almost all the herd-year types were related to each other with a varying number of transfers and introductions. More than $90 \%$ of the pairs between two herds were not renewed the next year. Assuming that movements were not controlled, within-herd prevalence was beta distributed averaging $15 \%$, and herd-level prevalence was $30 \%$, the theoretical risk of introducing an infected animal in herds without any fattening unit varied from 32 to $81 \%$. If herd testing was implemented and able to detect herds with a prevalence above $10 \%$ and if movements were not allowed from detected herds, the herd- and animal-level prevalences in the remaining herds became respectively $9 \%$ and $2 \%$ on average. The risk varied from 2 to $6 \%$ for herds without any fattening unit. Animal movements control may reduce the spread of pathogens.
\end{abstract}

cattle / movement / contact structure / Brittany

Résumé - Mouvements de bovins entre troupeaux en Bretagne et risque d'introduction d'animaux infectés. La propagation d'agents pathogènes entre troupeaux dépend fortement de la structure de contact entre troupeaux. Cette structure est liée aux relations de voisinage, aux mouvements d'animaux et à d'autres contacts infectieux. L'objectif de cette étude était de qualifier et de quantifier les mouvements de bovins entre troupeaux et leur hétérogénéité, pour évaluer le risque théorique d'introduire des animaux infectés dans les troupeaux. Les données collectées de 1998 à 2002 ont été

\footnotetext{
*Corresponding author: ezanno@vet-nantes.fr
} 
étudiées pour tous les troupeaux situés en Bretagne. Les types de troupeaux-année ont été définis à partir de la taille des troupeaux, du nombre de vaches par race et des ateliers d'engraissement (veaux de boucherie, taurillons). Les troupeaux-année étaient isolés (ni introduction ni transfert vers d'autres troupeaux), source fermés (pas d'introduction, au moins un transfert), source ouverts (introduction et transfert) ou de destination seulement (introduction, pas de transfert). Un tiers des troupeaux étaient des troupeaux-source ouverts et $16 \%$ étaient isolés. Les proportions variaient entre types de troupeaux-année et selon l'atelier d'engraissement. Les troupeaux ouverts avaient environ autant de troupeaux-source que d'animaux introduits dans l'année. La structure de contact entre troupeaux bovins était complexe et hétérogène. Presque tous les types de troupeaux-année étaient en relation les uns avec les autres avec un nombre variable de transferts et d'introductions. Plus de $90 \%$ des liens entre deux troupeaux ne duraient qu'une seule année. Sous l'hypothèse que les mouvements n'étaient pas contrôlés, que la prévalence intra-troupeau était distribuée selon une loi beta de moyenne $15 \%$, et que $30 \%$ des troupeaux étaient infectés, le risque théorique d'introduire un animal infecté dans les troupeaux sans atelier d'engraissement variait de 32 à $81 \%$. Si les troupeaux étaient testés par un test capable de détecter les troupeaux de prévalence supérieure à $10 \%$, et si les mouvements n'étaient pas permis depuis ces troupeaux détectés, les prévalences au niveau animal et au niveau troupeau dans les troupeaux restants devenaient respectivement $9 \%$ et $2 \%$ en moyenne. Le risque variait de 2 à $6 \%$ pour les troupeaux sans atelier d'engraissement. Le contrôle des mouvements animaux est un facteur de réduction de la propagation des agents pathogènes.

\section{bovin / mouvement / structure de contact / Bretagne}

\section{INTRODUCTION}

The spread of pathogens between animal populations can be either direct, i.e. between individuals, or indirect, i.e. via the environment, a vector or a reservoir species [7]. The direct transmission of pathogens between populations is related to the between-population contact rate and structure [5,11]. On the one hand, this contact structure is based on the spatial distribution of populations in an area and on neighbourhood relationships, which overall induce a local spread of pathogens. Other infectious contacts such as the application of slurry from another farm may also be involved. On the other hand, it is related to animal movements between populations (migration, dispersion), which could induce the spread of pathogens on large distances (for example, see [4,9]).

In a livestock area, domestic cattle are kept in herds. Each herd corresponds to a population, with its own dynamics and management system. Herds can be closedwith auto-renewal and no cattle introduced in the herd - or open - cattle being introduced. The introductions are related to the production types (i.e. rearing vs. fatten- ing). Moreover, the number of cattle in a herd needs to be managed to ensure a constant herd size; introductions of cattle from other herds can be inversely related to autorenewal.

The whole population of herds is a structured metapopulation, whose components (cattle herds) are related by the distance between herds and by animal movements (transfers and introductions). In order to manage animal health in such a complex dynamic structured system, the risk associated to the sources of introduction of transmittable pathogens into a herd has to be quantified. The introduction of infected cattle into a herd is one of the main routes of between-herd transmission for directly transmitted pathogens.

Among cattle infectious diseases, direct transmission is one of the main routes of transmission. Moreover, some of these diseases, such as Bovine Viral Diarrhoea Virus infections [8], bovine Johne's Disease [6] or the Foot-and-Mouth Disease [9], have important economic repercussions on cattle production.

Depending on the main production of the farms, several cattle herd types can be 
distinguished. They are related to the breed of reproductive cows (only dairy, only beef or both types of cows) and the presence of a fattening unit, such as a veal-calf or a bull fattening unit. Contact rate and structure may be assumed to vary between herd types. On the one hand, the contact structure between animals in a herd - and therefore, the within-herd transmission of some pathogens (for example see: [13, 14]) may vary between herd types. On the other hand, the types and intensities of animal movements may vary between herd types because of different management decisions concerning sales and introductions $[12,15]$. Hence, the between-herd contact structure may vary between herd types. Moreover, the risk of spreading a pathogen may also be related to the type of cattle (age, gender, breed) introduced into a herd. First, the type of animal introduced generally influences its infectivity and its susceptibility to a given pathogen (for example see: $[3,10])$. Second, it also influences the number and type of contacts made with other cattle in the source herd (i.e. the risk of being infected before being transferred to other herds) and in the herd of destination (i.e. the risk of infecting other cattle), in relation to the herd structure.

With more than 700000 dairy cows and $20 \%$ of French milk production, Brittany is the main area in France for dairy cattle farming [1]. This area was chosen as an example for studying animal movements between herds. The objective of the present study was to qualify and quantify the movements of cattle between herds and their heterogeneity, and to evaluate the theoretical risk of introducing an infected animal in a herd. After defining the types of cattle herds, we evaluated the proportion of open herds and source herds. The numbers and the characteristics of introduced and transferred cattle, as well as of the source and destination herds, were evaluated per herd type.

\section{MATERIALS AND METHODS}

\subsection{Data}

In French cattle herds, every animal is recorded within an identification scheme before 7 days of age. The data from Brittany were studied from 1998 to 2002 for all herds with one or more animals. Available data were the identification number of herds, and - per herd - the identification number of the animals, the gender, breed and birth date of the animals, the date of entry and reason for entry into the herd (birth, introduction), as well as the source herd when available, the date of exit and reason for exit from the herd (death, culling, transfer to another herd).

A movement was here defined as the exit of one animal from its source herd and the entry into its herd of destination. During this period, 35326 herds were referenced each year on average. They were of varying size (1 to 1115 referenced animals in a year). Seventy breeds were encountered. The main breeds were Holstein (57\% of all the cattle), Normandy $(10 \%)$ and Montbeliard (2\%) for dairy cattle, crossbred cattle (16\%), Charolais (5\%), Limousin $(4 \%)$ and Aquitaine Blond (3\%) for beef cattle. Crossbred cattle are not used for dairy production in this region. They were considered here as belonging to a beef production unit. Data included more than 8.8 million individual observations and more than 2.1 million animal movements. Source herds were recorded in $77 \%$ of the movements (Fig. 1).

\subsection{Definition of the herd-year types}

Herd types were defined on a yearly basis. A longer time step would have been problematic mostly because of a betweenyear variability in farmer strategies regarding cattle exits and introductions.

For each cycle going from the 1 st of April of the year X to the 31 st of March 
of the year X+1 (i.e. 4 cycles named 1998 to 2001) and each herd, the number of animals present at least one day in the herd was calculated. The average number of animals per herd per year was calculated by taking into account the number of days of presence per animal in the considered herd during the year. It was calculated per gender (male vs. female), type (beef, dairy or crosses) and age class. These numbers were used to define herd-year types. Limits for age classes were defined in agreement with the age at which animals are classically sold or transferred to other herds. As observed by inspection of the data, some animals were transferred older than expected (for example, some fattened dairy calves are sold at 7-8 months instead of 6 months of age). Hence, age classes were larger than classically defined. Five age classes were defined: [0-31 [ days (31 days being the maximum age of transfer considered for a dairy calf to be fattened), [18[ months ( 8 mo being the maximum age of transfer considered for a beef calf to be fattened), [8-20[ months (20 mo being the classical age at slaughter for a bull), [2030 [ months (young adults for replacement) and 30 months or more (adults for replacement).

Herd-years with less than 10 animals (i.e. 3650 animals-day) were grouped as "small herds" ('s'). In these herds, the breed of the animals was not considered, nor was the possible presence of a fattening unit. For larger herds, the types were defined relative to the number and the breed of cows ( $\geq 30$ months of age). A size of 15 to 20 adult cows is generally considered to be the minimum size for a production unit to be the main income source of a farmer [2]. To a dairy ('D') (respectively beef; 'B') unit corresponded to at least one adult dairy (respectively beef or cross-bred) cow. After inspection of the data (observed distributions), small dairy ('sD') and beef ('sB') units were defined as having each less than 15 adult cows. Herd- years without any adult cow belonged to three different types: herds with only dairy heifers (from 0 to maximum 30 months of age, 'Heif.'), herds with fattening veal calves only (from 0 to maximum 8 months of age; 'VCF'), and herds with fattening young bulls (at least one male older than 8 months; 'BF').

Among dairy and beef units, herd-years with males were also assigned a fattening unit. To account for the potential presence of reproductive males, two of the males older than 20 mo were not included in the definition of the fattening unit. The fattening unit was defined according to the age of males: veal-calf fattening (VCF; at least 2 males $<8$ mo and no male $\geq 8 \mathrm{mo}$ ) and bull-calf fattening (BF; at least 1 male $\geq 8 \mathrm{mo}$ ). The BF units also included bullock fattening (castrated males generally slaughtered after 30 mo of age). However, only $4 \%$ of the herds had 3 or more males older than 30 mo and could have been considered as having a bullock fattening unit. These herds were grouped with herds with a BF unit.

\subsection{Movement analysis}

Hereafter, herds that introduced at least one animal are named destination herds; herds that transferred at least one animal to another herd are named source herds. Source herds that introduced (or respectively did not introduce) animals are named open (respectively, closed) source herds. Herds that were only destination herds (i.e., no transfer of animals) are named strictly-destination herds. Herds that neither introduced not transferred animals are named isolated herds.

Among open herds, some introduced only 1 or 2 males for reproduction. These herds are closer to closed than to other open herds. Therefore, they were quantified.

For all the other herds, movements were qualified in relation to the type of source herds (herd-year types and localisation), 
the type of destination herds and the type of animals introduced (age, gender, breed). For each type of destination herds, the number of animals introduced per year and the number of source herds were calculated for an average herd-year. For each type of source herds, the number of animals transferred to other herds and the number of destination herds were calculated for an average herd-year. The number of pairs between one source and one destination herd was quantified, as well as the mean number of animals transferred per pair and the renewed presence of pairs between herds over the years. Means, percentiles and distributions were calculated. Lastly, flows of animals between herd-year types were synthesised: herd-year types were grouped, neglecting the size of the production unit. Dairy vs. beef herds represented former ' $\mathrm{D}$ ' and 'sD' herds vs. former ' $\mathrm{B}$ ' and ' $\mathrm{sB}$ ' herds. All herds with both a dairy and a beef unit (former 'D-B', 'sD-sB', 'D-sB', 'B-sD') were grouped as mixed herds. The presence of a fattening unit (none, VCF, $\mathrm{BF}$ ) was indicated. Small herds ('s'), specialised 'VCF' and 'BF' herds, and heifer herds were considered separately.

\subsection{Theoretical risk of introducing infected cattle}

The risk of introducing infected cattle into a herd is a function of the proportion of infected source-herds (herd-level prevalence), the within-herd prevalence in infected source-herds, and the number of introduced animals. We propose here a simple model as a first approach for assessing this risk:

$$
\text { risk }=1-\left[1-\left(p_{\text {herd }}\right)\left(p_{\text {animal }}^{\text {mean }}\right)\right]^{n},
$$

with $p_{\text {herd }}$ the herd-level prevalence, $p_{\text {animal }}^{\text {mean }}$ the average within-herd prevalence in infected herds, and $n$ the number of purchased animals per herd.

This model is based on three assumptions: all the animals have the same prob-

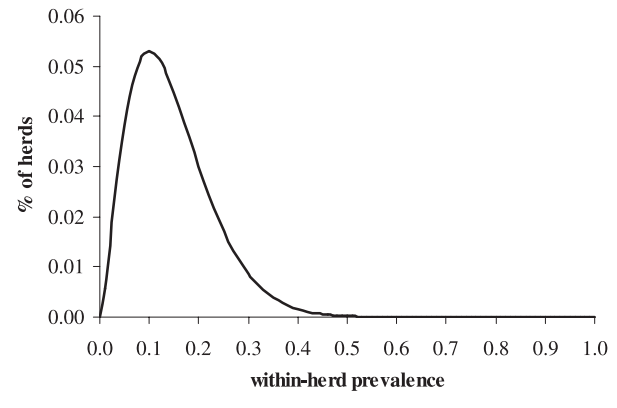

Figure 1. Distribution of the within-herd prevalences in infected herds following a beta distribution of mode $10 \%$ and mean $15 \%$.

ability of being purchased, whatever their herd; all the animals have the same probability of being infected if they belong to an infected herd; all the herds have the same probability of being infected.

As an example, $30 \%$ of the herds were chosen as being infected $\left(p_{\text {herd }}\right)$. In order to account for the variability of the within-herd prevalence in infected herds, this prevalence was beta distributed with a mode of $10 \%$ and an average of $15 \%$ (Fig. 1). The numerical values were arbitrarily chosen. The model was applied to the previously described average numbers of introduced animals per herd and per year for each herd-year type (Tab. I) and each fattening unit (none, VCF, BF). Three cases were represented: no control of animal movements vs. restriction of animal movements from detected herds with a test that detects all herds with a prevalence (1) above $30 \%$; (2) above $10 \%$.

\section{RESULTS}

\subsection{Animals involved in between-herd movements}

Male dairy calves ( $0-1 \mathrm{mo})$ represented $47 \%$ of the animals involved in betweenherd movements (Fig. 2). Beef calves (males and females of $0-1$ mo of age) represented $20 \%$ of the transferred animals. 
Table I. Definition, average yearly number of herds (average herd size in brackets) per herd-year type (s: small herd, D: dairy unit, B: beef unit, Heif.: heifers, VCF: veal-calf fattening, BF: bull fattening).

\begin{tabular}{|c|c|c|c|c|c|c|c|}
\hline \multirow[t]{2}{*}{ \# cattle } & \multirow{2}{*}{$\begin{array}{c}\# \text { dairy cows } \\
(\geq 30 \mathrm{mo})\end{array}$} & \multirow{2}{*}{$\begin{array}{c}\text { \# beef cows } \\
(\geq 30 \mathrm{mo})\end{array}$} & \multirow{2}{*}{$\begin{array}{c}\text { Main herd } \\
\text { type }\end{array}$} & \multicolumn{3}{|c|}{ Fattening unit } & \multirow[b]{2}{*}{ TOTAL } \\
\hline & & & & none & $\mathrm{VCF}$ & $\mathrm{BF}$ & \\
\hline$<10$ & - & - & $\mathrm{s}$ & $7611(4)$ & - & - & $7611(4)$ \\
\hline \multirow[t]{13}{*}{$\geq 10$} & $\geq 15$ & 0 & D & $9044(65)$ & 761 (107) & 4408 (101) & $14213(78)$ \\
\hline & & $>0$ and $<15$ & D-sB & $1460(67)$ & $421(90)$ & 3485 (110) & 5365 (97) \\
\hline & & $\geq 15$ & D-B & $85(108)$ & $50(104)$ & $1124(168)$ & $1258(162)$ \\
\hline & $>0$ and $<15$ & 0 & $\mathrm{sD}$ & $1130(19)$ & $62(56)$ & $220(35)$ & $1412(23)$ \\
\hline & & $>0$ and $<15$ & $\mathrm{sD}-\mathrm{sB}$ & $476(20)$ & $133(32)$ & $527(35)$ & $1136(28)$ \\
\hline & & $\geq 15$ & B-sD & $45(57)$ & $63(62)$ & 346 (106) & $454(95)$ \\
\hline & 0 & 0 & Heif. & $25(44)$ & - & - & $25(44)$ \\
\hline & & & VCF & - & 306 (190) & - & 306 (190) \\
\hline & & & $\mathrm{BF}$ & - & - & $286(108)$ & $286(108)$ \\
\hline & & $>0$ and $<15$ & sB & 763 (19) & $120(61)$ & $616(36)$ & $1500(29)$ \\
\hline & & $\geq 15$ & B & 343 (55) & 102 (79) & $1311(117)$ & $1756(103)$ \\
\hline & & & Others & $6(45)$ & - & - & $6(45)$ \\
\hline & & & TOTAL & 20988 & 2017 & 12322 & 35326 \\
\hline
\end{tabular}

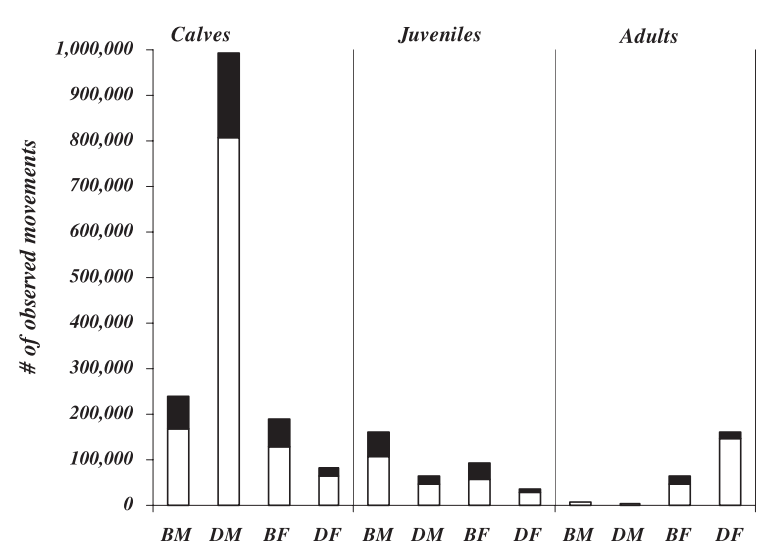

Figure 2. Number of observed introductions from April 1998 to March 2002 in Brittany (France) with a recorded (white) vs. not recorded (black) source herd, per type of animal: gender (M: male; F: female), breed (B: beef; D: dairy) and age (calves: 0-1 month old; juveniles: 1-20 month old; adults: $\geq 20$ month old).

Eighty-seven percent of these beef calves were crossbred.

Dairy females were transferred essentially after 20 mo of age ( $57 \%$ of the transferred dairy females). They were the main group (67\%) among transferred adults. Dairy females transferred after 20 mo of age represented $4 \%$ of all the dairy females older than 20 mo. Beef and crossbred females transferred after 20 mo of age represented $7 \%$ of all the beef and crossbred females older than 20 mo.

\subsection{Herd-year types}

The number of herds and their average size including young stock are given 
in Table I per herd-year type for an average year. Large dairy herds ('D') and small herds ('s') were the two most frequent types, representing respectively $40 \%$ and $22 \%$ of the herds.

When excluding small ('s') herds that by definition did not have a fattening unit, $8 \%$ of the herds had a VCF unit and $44 \%$ of them had a BF unit. The proportion of herds without a fattening unit was higher in dairy herds ('D': 64\%; 'sD': 80\%). When excluding these herds, $74 \%$ of the remaining herds had a fattening unit.

The average number of adult cows per herd-year (in all except 'Heif.', 'VCF' and ' $\mathrm{BF}$ ' herds) varied within herd-year types and was slightly higher in dairy than in beef unit: from 30 to 41 dairy cows in herds with a large dairy unit, from 5 to 10 dairy cows in herds with a small dairy unit, from 23 to 37 beef cows in herds with a large beef unit, from 3 to 7 beef cows in herds with a small beef unit, 2 adult cows in small herds.

Since the type of each herd was defined each year of the survey, the herd-year type of a given herd could change from one year to the next. More than $50 \%$ of the herds kept the same type and the same fattening unit from one year to the next. More than $90 \%$ of the herds with a large production unit ('D', 'B', 'D-B') and of the 's' herds kept the same type. Ninety percent of the herds without a fattening unit on a given year also did not have any fattening unit the following year.

\subsection{Herds' participation to animal movements}

Among all the herds, $44 \%$ were destination herds and $73 \%$ were source herds.

Isolated herds represented $16 \%$ of the herds (see the yearly number of herd-years in Fig. 3). Half the 's' herds were isolated. They represented $65 \%$ of the isolated herds. Other herd-year types were in much lower proportions, with dairy herds ('D') being the second most frequent type representing $8 \%$ of the isolated herds. Among isolated herd-years, $15 \%$ were isolated for the four successive cycles (from 1998 until 2001) and could be considered as strictly isolated herds.

Open source herds represented $33 \%$ of the herds. Among heifer herds, $83 \%$ were open source herds, but representing only $0.2 \%$ of this category. Depending on the herd-year type and the fattening unit, open source herds represented $22 \%$ to $62 \%$ of the herds, except in 's' herds $(10 \%)$. The proportions were smaller in herds without a fattening unit. Dairy herds ('D') without a fattening unit were the main group of open source herds (26\%). All the 'D' herds represented $44 \%$ of the open source herds. All the 'D-sB' herds represented $20 \%$ of this category. The other herd-year types represented each less than $7 \%$ of it.

Among destination herds, $12 \%$ (i.e. $5 \%$ of all the herds) introduced only 1 or 2 males older than 20 months for reproduction.

\subsection{Transfers of cattle per herd-year type and fattening unit}

When excluding small herds ('s') and specialised fattening herds ('VCF', 'BF'), $87 \%$ of the remaining herds were source herds $(90 \%$ of the herds without a fattening unit or with a VCF unit and $83 \%$ of the herds with a BF unit; Fig. 3).

As expected, the average yearly number of animals per source herd and the type of animals transferred to other herds varied largely between herd-year types (Tab. II). The presence of a fattening unit had almost no influence (results not shown). The number of transferred animals increased with the number and the size of the production units. However, the rate of animal transfers was larger in herds with a small production unit than in herds with a large one of the same type (' $D$ ' or ' $\mathrm{B}$ ' or 'D-B'). On average per year, ' $\mathrm{s}$ ' 

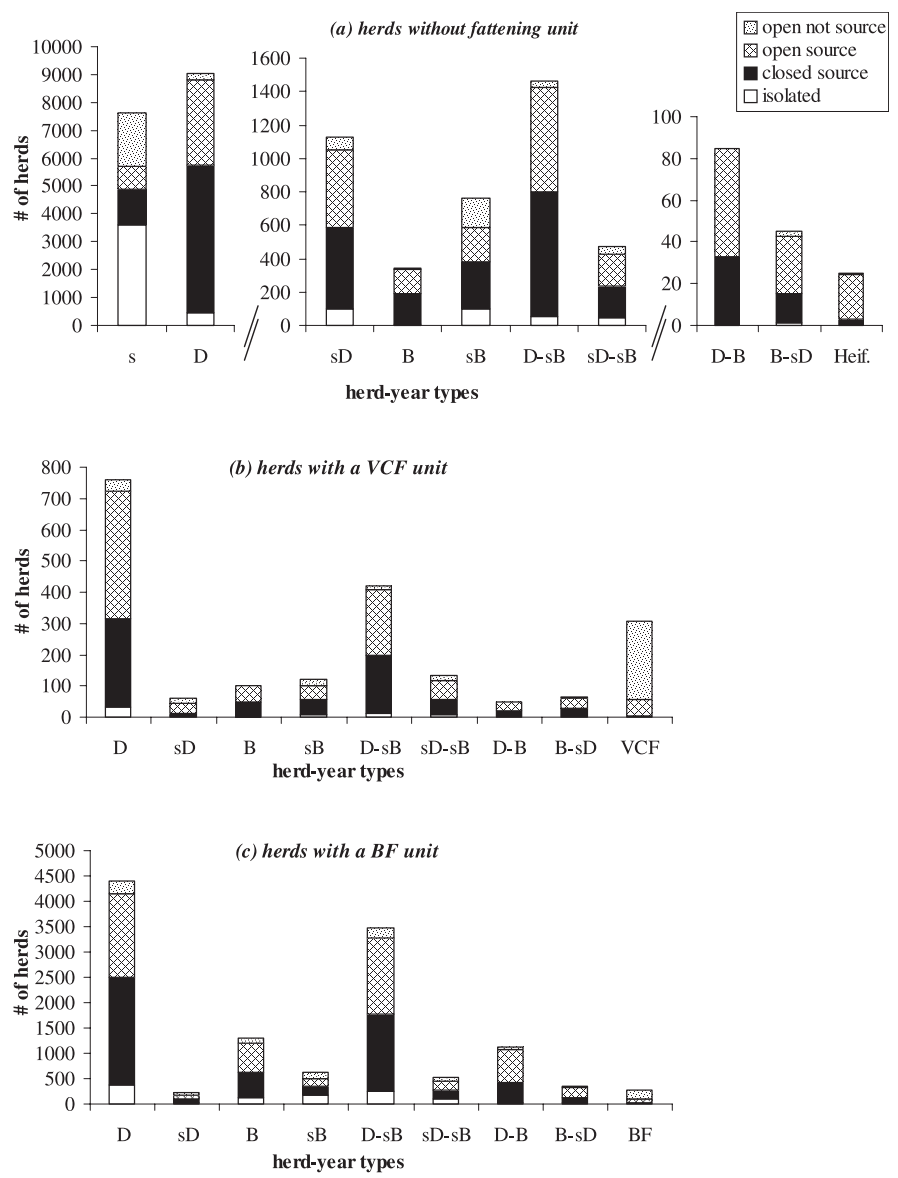

Figure 3. Average yearly number of herd-years, per type and fattening unit (see Tab. I): (a) no fattening unit (with three different scales); (b) VCF unit; (c) BF unit. Herd-years are categorised as isolated (white; no transfer, no introduction), closed source (black; transfers but no introduction), open source (hatching; transfers and introductions), strictly destination (dotted; introductions but no transfer).

source herds transferred 3 animals; herds with only small units ('sD', 'sB', 'sD-sB') transferred less than 10 animals; herds with 1 large unit ('D', 'B', 'D-sB', 'B-sD') and heifer herds transferred 10 to 20 animals; herds with two large units ('D-B') transferred 20 to 30 animals. Unexpectedly, specialised fattening herds ('VCF', 'BF') also transferred on average 10 to 20 animals. However, the distribution was very skewed with a low median and few high values.
As expected, mainly dairy herds (' $\mathrm{D}$ ', 'sD', 'D-sB', 'D-B') transferred preferentially [0-1[ mo calves ( 50 to $75 \%$ of the transfers; Tab. II); mainly beef herds ('B', 'sB', 'B-sD') transferred preferentially [120[ mo cattle ( 65 to $75 \%$ of the transfers). Females older than 20 mo represented 14 to $18 \%$ of the transfers from herds with at least a large production unit ('D', 'B', 'D-B', 'D-sB', 'B-sD'); they represented 25 to $39 \%$ of the transfers from herds with 
Table II. Yearly number per source herd of cattle transferred to other herds of a given herd-year type (see Tab. I): mean, percentiles 50 and 95, and proportions of calves (0-1 mo) juveniles (1-20 mo) and females older than 20 mo in the transfers.

\begin{tabular}{lccccccc}
\hline \multirow{2}{*}{ Herd-year type } & \multicolumn{4}{c}{ \# of cattle } & & \multicolumn{3}{c}{$\%$ of the transfers } \\
\cline { 2 - 3 } \cline { 7 - 8 } & Mean & Perc. 50 & Perc. 95 & & {$[0-1[$ mo } & {$[1-20[$ mo } & Females $\geq 20$ mo \\
\hline s & 3 & 2 & 8 & & $18 \%$ & $33 \%$ & $45 \%$ \\
$\mathrm{D}$ & 13 & 11 & 34 & & $74 \%$ & $7 \%$ & $18 \%$ \\
$\mathrm{sD}$ & 8 & 6 & 24 & & $47 \%$ & $13 \%$ & $39 \%$ \\
$\mathrm{~B}$ & 18 & 14 & 48 & & $7 \%$ & $76 \%$ & $14 \%$ \\
$\mathrm{sB}$ & 7 & 5 & 18 & & $7 \%$ & $64 \%$ & $25 \%$ \\
$\mathrm{D}-\mathrm{sB}$ & 14 & 12 & 36 & & $71 \%$ & $10 \%$ & $17 \%$ \\
$\mathrm{sD}-\mathrm{sB}$ & 8 & 6 & 22 & & $36 \%$ & $30 \%$ & $30 \%$ \\
$\mathrm{D}-\mathrm{B}$ & 22 & 18 & 52 & & $57 \%$ & $26 \%$ & $15 \%$ \\
$\mathrm{~B}-\mathrm{sD}$ & 20 & 15 & 57 & & $15 \%$ & $64 \%$ & $17 \%$ \\
Heif. & 21 & 14 & 49 & & $0 \%$ & $17 \%$ & $83 \%$ \\
VCF & 15 & 1 & 102 & & $55 \%$ & $45 \%$ & $0 \%$ \\
BF & 16 & 2 & 58 & & $10 \%$ & $71 \%$ & $1 \%$ \\
\hline
\end{tabular}

only small production units ('sD', 'sB', 'sD-sB'). As expected, they were the main type of transferred animals from heifer herds $(80 \%)$, but also from 's' herds $(45 \%)$.

\subsection{Introduction of cattle per herd-year type and fattening unit}

\subsubsection{Destination herds}

Whatever the herd-year type, the proportion of destination herds per herd-year type was much lower than the proportion of source herds (Fig. 3). When excluding small herds (s) and specialised fattening herds (VCF, BF), $45 \%$ of the remaining herds were destination herds, this proportion being smaller in herds without a fattening unit $(40 \%)$ than in other herds $(57 \%$ of the herds with a VCF unit; $49 \%$ of the herds with a BF unit). Only $36 \%$ of the dairy herds (D) without a fattening unit were destination herds, compared to more than $45 \%$ of the herds in the other herdyear types without a fattening unit. More than $80 \%$ of the 'sD' herds with a VCF unit were destination herds, against less than $65 \%$ of the herds in the other herd-year types with a VCF unit.
The average yearly number of introductions per destination herd was influenced by the herd-year type. As expected, it was much higher if a fattening unit (especially a VCF) was present (Fig. 4a). The numbers of introductions were highly variable within herd-year types, especially in herds with a fattening unit (Figs. 4b, 5).

\subsubsection{Introductions into herds without a fattening unit}

Half the open herds without a fattening unit introduced from 1 to 3 animals per year (Fig. 5a). Twenty-five percent introduced more than 6 animals. The number of introductions increased with the presence of a beef production unit (Fig. 4a). Open 's' herds introduced an average of 3 animals per year, with $33 \%$ of the 's' herds introducing only 1 animal. Heifer herds introduced an average of 26 animals. In herds without a fattening unit, 0-1 mo calves represented less than $22 \%$ of the introductions. However, more than $25 \%$ of the herds introduced at least 1 calf $(0-$ $1 \mathrm{mo}$ ) or 1 juvenile (1-20 mo). Mainly females older than 20 mo were introduced, 


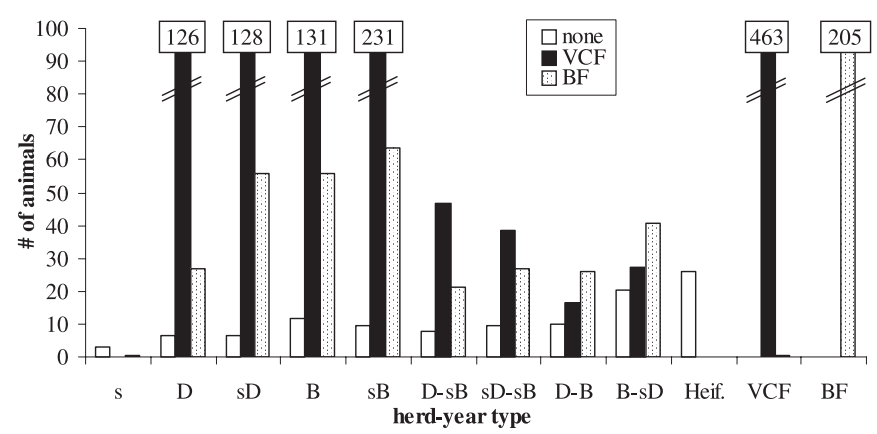

(a)

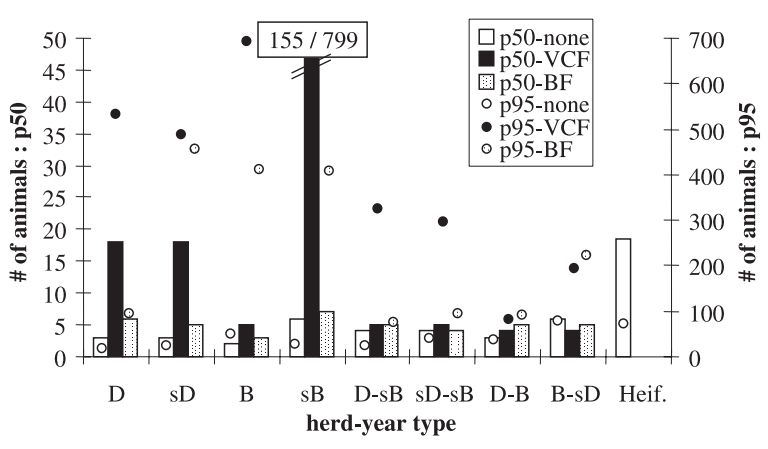

(b)

Figure 4. Average yearly number of introduced cattle per destination herd, for each herd-year type (see Tab. I) and fattening unit (white: no fattening unit; black: VCF unit; dotted: BF unit): (a) mean number; (b) 50 (histogram) and 95 percentiles (circle). The exact values of the associated percentiles are boxed in numbers (p50/p95). 'VCF' (p50 = 385; p95 = 1044), 'BF' (p50 = 79; p95 = 1026) and 's' (p50 = 2; p95 = 9) herd types are not represented.

representing more than half the introductions in all herd-year types except ' $\mathrm{sB}$ ' herds $(22 \%)$. As expected, hardly any dairy males were introduced and the breed of the introduced females was closely related to the main production unit $(\mathrm{D}, \mathrm{B}$ or both; Fig. 5a). As expected, the number of introductions of dairy females and of animals older than 20 mo were highly variable.

\subsubsection{Introductions into herds with a fattening unit}

Herds with a VCF or BF unit had a similar heterogeneity in the number of introductions of cattle older than 20 mo than herds without such units (Fig. 5).
As expected, specialised fattening herds introduced the highest number of animals with an average of more than 200 animals per year. Among other herds with a fattening unit, dairy ('D', 'sD') and beef ('B', 'sB') herds introduced more animals than mixed herds ('D-sB', 'B-sD', 'sD-sB', 'D-B'). The proportion of dairy males in the introductions varied from 20 to $70 \%$ and the proportion of dairy females in the introductions was less than $30 \%$.

Among herds with a VCF unit, 25\% introduced more than 300 animals (Fig. 5b), whereas $50 \%$ introduced less than 25 animals. Among specialised 'VCF' herds, 95\% introduced more than 100 animals and half introduced more than 385 animals. 

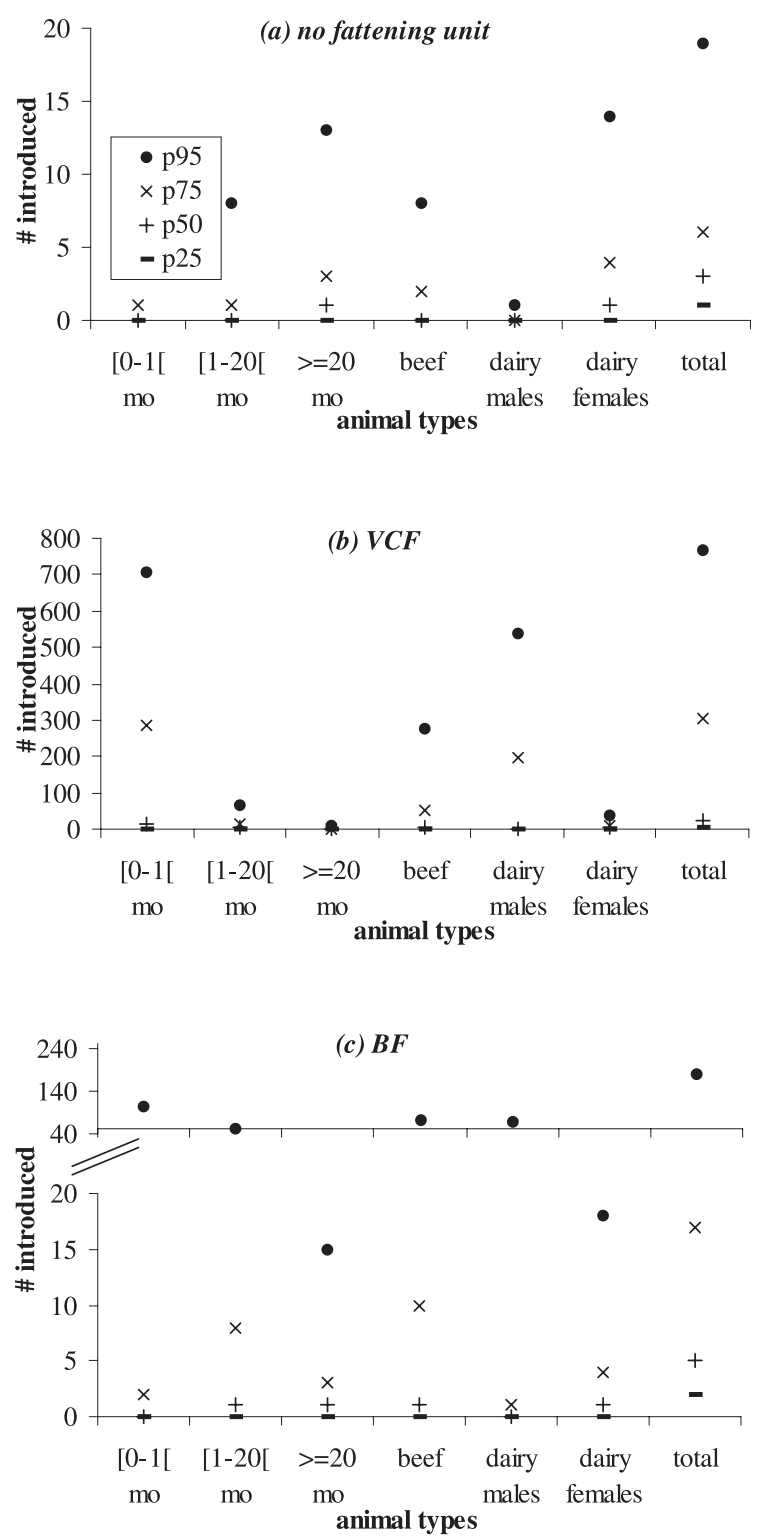

Figure 5. Percentiles (25, 50, 75 and 95 ) of the number of introductions per animal type (calves $(0-1$ month old), juveniles (1-20 month old), adults ( $\geq 20$ month old), beef animals, dairy males, dairy females), per type of fattening unit (a: none, b: VCF, c: BF).

Among dairy herds ('D') with a VCF unit, 50\% introduced less than 18 animals (Fig. 4b), but 25\% introduced more than 170 animals. Calves (0-1 months old) were the main type of introduced animals (Fig. 5b), representing on average 60 to $90 \%$ of the yearly introductions, depending on the herd-year types. Beef animals (including around $40 \%$ of cross-bred animals) represented 20 to $35 \%$ of the introductions. The number of introductions of $0-1$ mo calves and of dairy males were the most variable (Fig. 5 b), with $25 \%$ of these herds introducing more than 200 dairy males. 
Introductions were also heterogeneous between herds with a BF unit. Half these herds introduced less than five animals (Fig. 5c), whereas $10 \%$ introduced more than 64 animals. Among specialised 'BF' herds, 25\% introduced more than 200 animals and $25 \%$ introduced less than 20 animals. The number of introductions of 120 mo and of beef animals were the most variable (Fig. 5c). Calves ( $0-1$ months old) were the main type of introduced animals, representing overall $60 \%$ of the introductions. Dairy males represented overall $45 \%$ of the introductions, with some herds introducing a large number of dairy males (e.g. $5 \%$ of the 'sD', 'B' and 'sB' herds introduced more than 200 dairy male $0-1$ mo calves; $10 \%$ of the specialised 'BF' herds introduced more than 400 dairy male 01 mo calves). Beef animals (males and females) represented overall $44 \%$ of the introductions, including around half crossbred animals.

\subsection{Relationships between source and destination herds}

In $80 \%$ of the pairs between one source and one destination herd, only one animal was concerned in a given year. In $99 \%$ of these pairs, less than seven animals were concerned, the maximum number being 287 animals for one pair in a year.

Open source herds with both more than 10 destination herds and more than 10 source herds represented at least $0.5 \%$ of the herds (i.e. 180 herds-year). Open source herds transferring more than 30 animals and introducing more than 10,30, or 50 animals represented respectively $3,1.3$ and $0.7 \%$ of the whole population of herds (i.e. respectively 918, 459 and 230 herdsyear).

\subsubsection{Number of source herds per destination herd}

The number of source herds per destination herd per year was closely related to the number of animals introduced in the herd, i.e. to the fattening unit and the herd-year type (Fig. 6). Forty-five percent of the destination herds had only one source herd and $19 \%$ had two source herds. The maximum number of source herds was 787 herds.

Overall, herds without a fattening unit had on average 2.4 source herds, $95 \%$ having less than 7 source herds. All herd-year types had less than four source herds on average, except 'B-sD' herds and heifer herds. More than half the 'B-sD' herds had less than two source herds, whereas $20 \%$ had more than 10 source herds (Fig. 6a). Half the heifer herds had more than six source herds, with $5 \%$ having more than 22 source herds.

Overall, herds with a VCF unit had an average of 51.2 source herds, with half having less than 8 source herds and $10 \%$ having more than 160 source herds. The number of source herds varied strongly within and between herd-year type. More than $60 \%$ of the specialised 'VCF' herds had more than 70 source herds (Fig. 6b). Forty percent of the 'sB' herds had more than 70 source herds, with $25 \%$ having more than 120 source herds. On the contrary, more than $90 \%$ of the 'D-B' herds had less than five source herds. In between, in herd-year types such as 'D', 'sD' and ' $\mathrm{B}$ ', half the herds had less than 10 source herds whereas almost $20 \%$ of the herds had more than 70 source herds (Fig. 6b).

Overall, the herds with a BF unit had an average of 10.8 source herds, with half having less than 2 source herds and 5\% having more than 42 source herds. Specialised 'BF' herds had an average of 60 source herds (Fig. 6b), with $47 \%$ having less than 10 source herds and $10 \%$ having more than 190 source herds. In all herdyear types, $75 \%$ of the herds at least had less than five source herds (Fig. 5b). In the mixed ('D-B', 'sD-sB', 'D-sB', 'B-sD') and the dairy ('D') herd-year types, $5 \%$ of the herds had more than 18 to 33 source herds (depending on herd type); in the other herd-year types ('sD', 'B', 'sB'), 

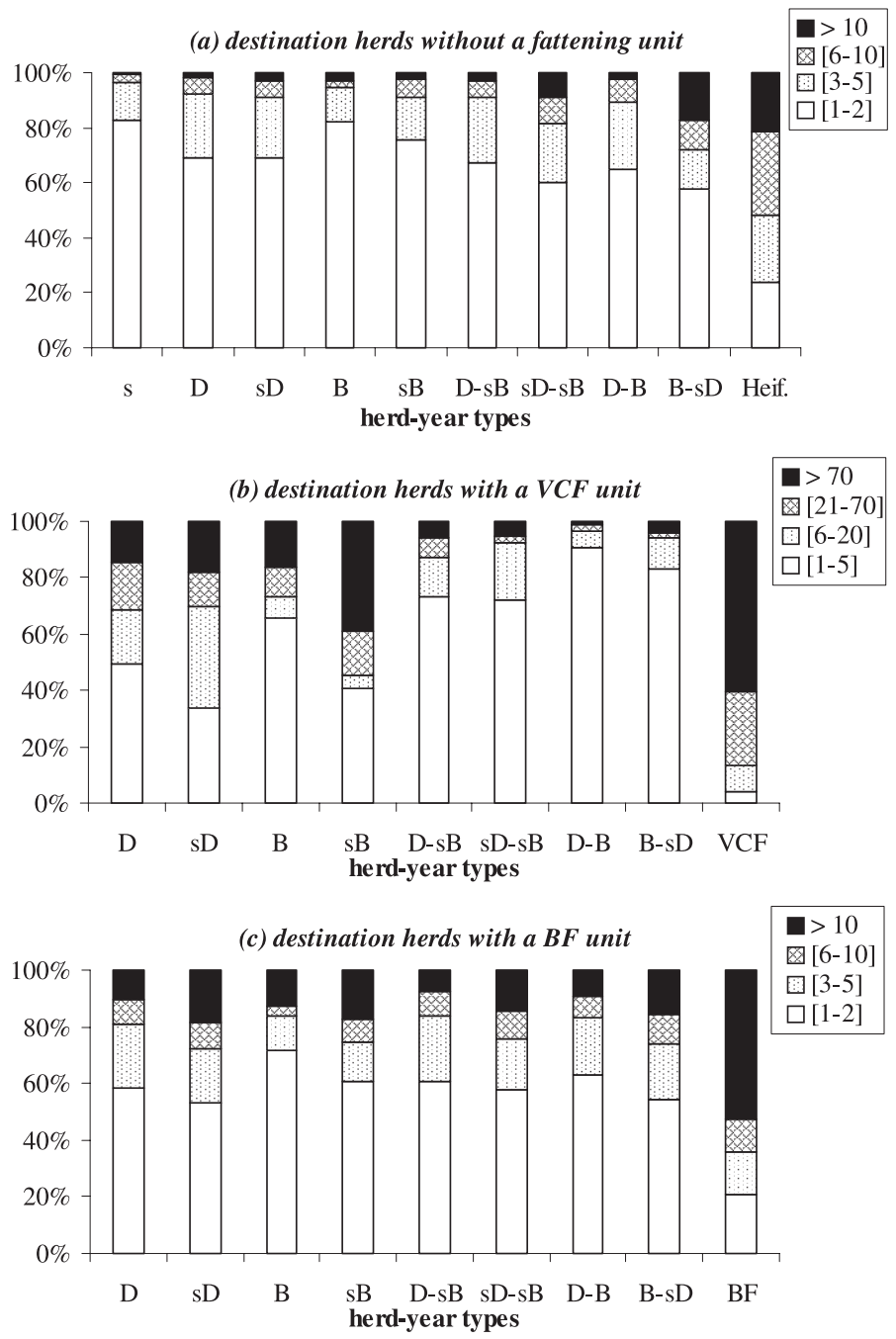

Figure 6. Proportions of destination herds per herd-year type (see Tab. I) and fattening unit (a: no fattening unit; b: VCF unit; c: BF unit) having $x$ source herds (white: [1-2] source herds in (a) and (c), [1-5] in (b); dotted: [3-5] in (a) and (c), [6-20] in (b); hatching: [6-10] in (a) and (c), [21-70] in (b); black: $>10$ in (a) and (c), $>70$ in (b)).

at least $5 \%$ of the herds had more than 100 source herds.

\subsubsection{Number of destination herds per source herd}

The number of destination herds per source herd per year depended mainly on the herd-year type (Fig. 7), without any influence of the presence of a fattening unit. Source herds had an average of 6 destination herds, $18 \%$ of the herds having only one destination herd and $12 \%$ two destination herds. The maximum number of destination herds was 60 herds, with more than $20 \%$ of the herds with a large dairy unit 


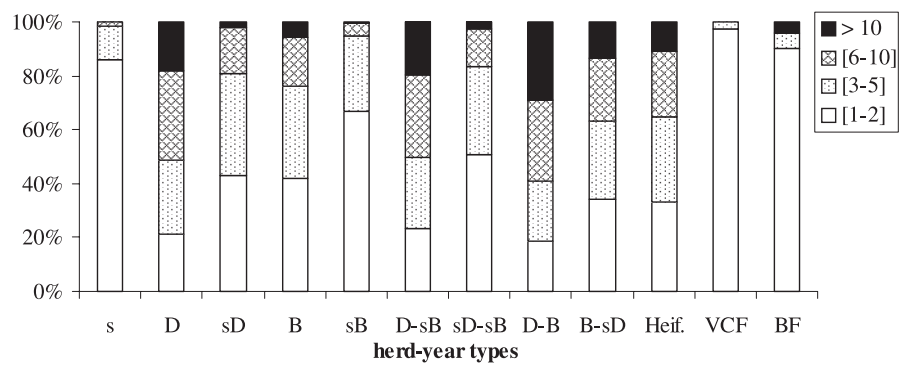

Figure 7. Proportions of source herds per herd-year type (see Tab. I) having [1-2], [3-5], [6-10] or $>10$ destination herds.

('D', 'D-sB' and 'D-B') having more than 10 destination herds (Fig. 7).

\subsubsection{Stability of the relationships over the years}

The renewed presence of pairs between herds over the years concerned only $7 \%$ of the pairs for two consecutive years and $2 \%$ for four consecutive years. Two herds paired for two consecutive years had a greater chance to be paired longer, i.e. $20 \%$ and $60 \%$ of the herds paired for respectively 2 and 3 consecutive years were actually paired for four consecutive years. Among pairs renewed for at least three consecutive years, destination herds without a fattening unit were more represented than among all the pairs ( 27 vs. $13 \%$ of the destination herds), whereas destination herds with a VCF unit were less represented (33 vs. $45 \%$ ). No difference was found in the type of source herds.

\subsection{Localisation of the source herds and of the introduced animals}

Since most pairs between one source and one destination herd concerned one animal, the geographical origin of animals introduced in a given destination herd was almost equivalent to the geographical origin of its source herds. Here, we only present the geographical origin in terms of introduced animals.
On average, $52 \%$ of the introduced animals came from outside Brittany, 23\% outside of the western-France area (Brittany, Pays de la Loire, Lower-Normandy). In herd-years without a fattening unit, with a VCF unit or with a BF unit, the proportion of introductions coming from source herds located in Brittany averaged respectively $85 \%, 39 \%$ and $49 \%$. This proportion averaged $81 \%$ and $96 \%$ of the introductions in 's' and heifer herds, respectively. It averaged $38 \%$ and $42 \%$ of the introductions in specialised 'VCF' and 'BF' herds.

\subsection{Flow of animals between herd-year types}

The average number of animals transferred per year from one source herd to one destination herd was 1 to 3 animals, depending on the herd-year type.

Globally, cattle movements from dairy, mixed and beef herds represented respectively $57 \%, 31 \%$ and $10 \%$ of all the observed cattle movements, whereas these herds represented respectively 44, 23 and $9 \%$ of the herd-years. Movements from dairy herds without a fattening unit represented $38 \%$ of the movements, those from mixed herds with a BF unit of $20 \%$, and those from dairy herds with a BF unit of $15 \%$. The other types of source herds represented each less than $6 \%$ of the movements. Cattle movements from dairy herds 
without a fattening unit to specialised 'VCF' herds represented $10 \%$ of the movements. Cattle movements from dairy herds without a fattening unit to other dairy herds without a fattening unit represented $5 \%$ of the movements. These two flows were the largest ones. Movements from small herds ('s') represented $2 \%$ of the movements. Globally, movements to dairy, mixed and beef herds represented respectively $31 \%$, $22 \%$ and $15 \%$ of the movements. Movements to specialised 'VCF' and 'BF' herds represented respectively $21 \%$ and $8 \%$ of the movements. Movements to 's' herds represented $3 \%$ of the movements. Movements from and to heifer herds were a very low proportion of the movements (less than $0.2 \%)$.

On average, dairy and mixed source herds had six destination herds, mainly of dairy type with a VCF unit, or specialised $\mathrm{VCF}$ and BF herds. Beef herds had three destination herds, mainly of mixed type with a BF unit. Heifer herds had three destination herds, mainly of dairy type without a fattening unit. Small herds ('s') had only one destination herd, with two animals exported per year per small source herd.

The number of source herds per year per destination herd was close to the number of animals introduced per year per destination herd, because generally only one animal was transferred each time. Only the number of source herds is presented hereafter (Fig. 8). Dairy herds without a fattening unit was the main type of source herd: all herd-year types of destination herds except beef herds without a fattening unit and small herds - introduced animals from 1 to 53 of dairy herds. Herds without a fattening unit had less than three source herds on average, which were mainly dairy herds without a fattening unit. As expected, herds with a fattening unit had more source herds, mainly of dairy type without a VCF fattening unit. As expected, herds with a VCF unit were not classical source herds, and were only source herds for other herds with a VCF unit or for specialised fattening herds. Movements to small herds concerned on average two animals and one source herd.

\subsection{Theoretical risk of introducing an infected cattle}

For $30 \%$ of infected herds and $15 \%$ of infected animals per infected herd on average (Fig. 1), the risk was higher than $30 \%$ for all herd-year types (Fig. 9a). It varied from 32 to $81 \%$ for herds without any fattening unit and from 75 to 100 for herds with a fattening unit (VCF or BF).

When implementing a herd test detecting all herds with a prevalence above $30 \%$ and when preventing detected herds from being source-herds, the risk remained almost the same. Among remaining sourceherds, the herd-level prevalence decreased only to $28 \%$ and the average within-herd prevalence to $13 \%$.

For a better test detecting all herds with a prevalence above $10 \%$, the risk highly decreased (Fig. 9b). The herd-level prevalence decreased to $9 \%$ and the average within-herd prevalence to $2 \%$.

As a general example, herds introducing one animal per year had a risk of introducing an infected animal of 5\% if no control, $4 \%$ with the first test, and $0.2 \%$ with the second test. Herds introducing five animals per year had a risk of respectively 21,17 and $1 \%$. If 100 animals were introduced, the risks became respectively $99 \%$, $98 \%$ and $16 \%$.

\section{DISCUSSION}

\subsection{Method to describe between-herd animal movements}

The method used here to define the types of cattle herds in Brittany is only related to the presence or absence of animals 


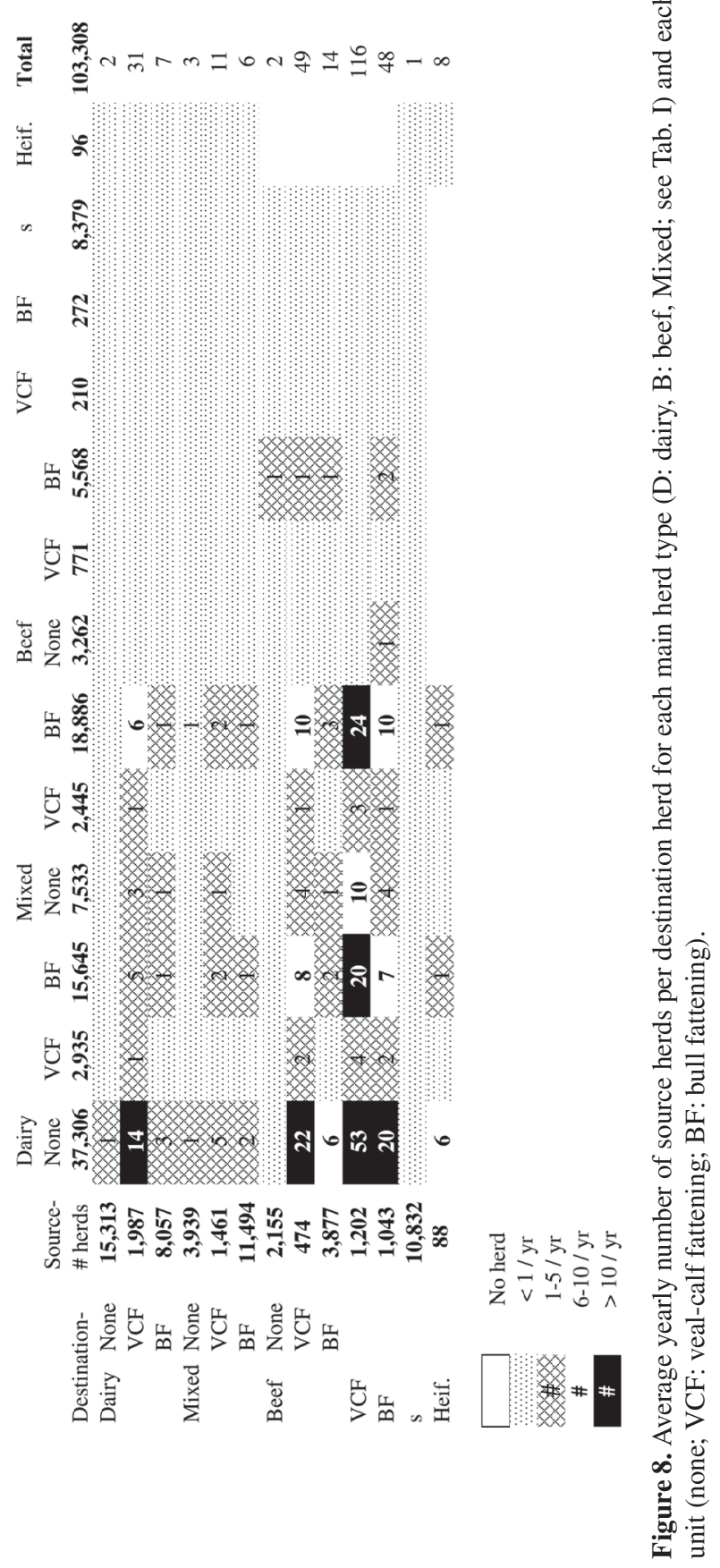



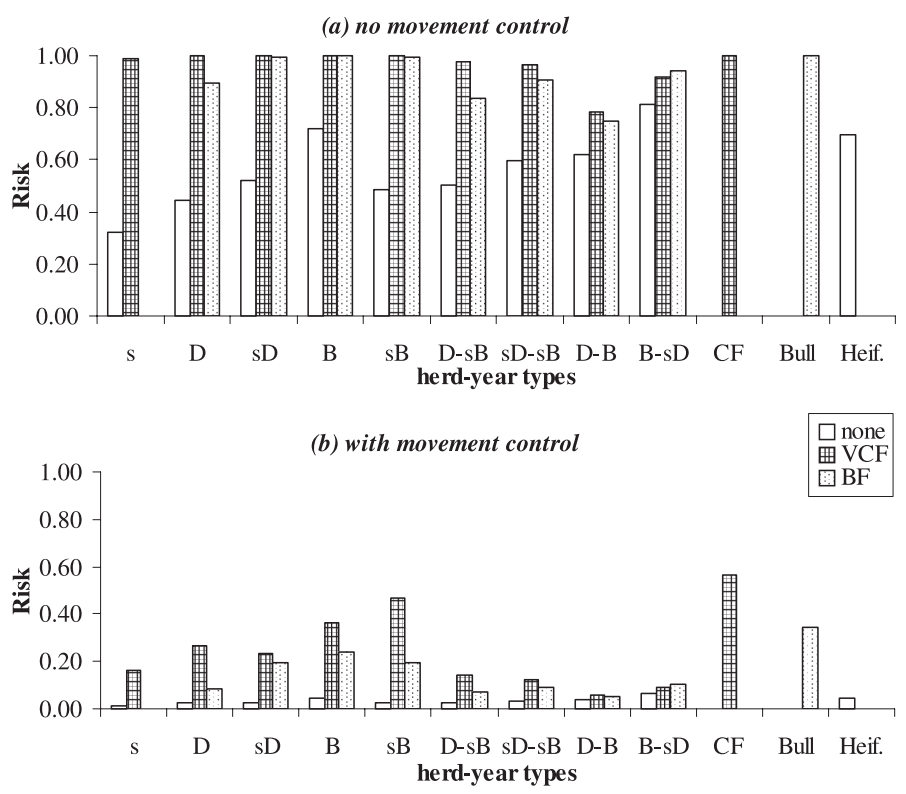

Figure 9. Theoretical risk of introducing an infected animal into a herd per herd-year type (see Tab. I) and fattening unit (none; VCF: veal-calf fattening; BF: bull fattening) for a beta distributed prevalence of mean $15 \%$ (Fig. 1) and a herd-level-prevalence of $30 \%$ (a) without any control; (b) with a test detecting all herds with a prevalence above $10 \%$, movements from these herds being not allowed.

per category and the size of each production unit in animals-day. Hence, because animal movements were not used in their definition, the herd types could be used to describe variations in the numbers and types of between-herd movements. However, as a consequence of our choices to define herd types, it was not possible to identify herds with both a veal-calf fattening unit and a bull fattening unit from herds with only a bull fattening unit. Hence, both herd types were grouped and defined as having a bull fattening unit. To distinguish between these herd types, the age of animals being slaughtered should have been taken into account.

The type of each herd was defined for each year of the survey. A yearly time step was chosen for two reasons. First, changes in farmer's decision between years, such as stopping or starting a fattening unit, could be accounted for. Second, the time step was long enough to characterise herd structure regardless of its variability over the oneyear production cycle.

The between-herd flow of cattle was highly variable between herd-year types and fattening units, but also within herdyear types. This confirms that mean values are not sufficient to describe between-herd animal movements. The percentiles and the distributions provide a description of this heterogeneity.

The method is adaptable to other livestock areas. However, if the range of the unit sizes may be equivalent in other areas (15 to 20 cows; [2]), the exact value to define thresholds was chosen here by inspection of observed data and may change for other areas. If the herd type definition may be the same as described here, animal movements may differ between livestock 
areas, mainly because of a change in the dominant breed and livestock farming system (i.e. dairy versus beef production system). The number and the types of the animals available for replacement or fattening is therefore likely to change. The number of herds in the area, i.e. the area-specific herd density, may also influence the number of pairs between herds.

\subsection{Between-herd network due to animal movements}

A very large proportion of herds were involved in animal movements whatever the herd-year type: when excluding small herds ('s'), 94\% of the herds were not classified as isolated herds. Among destination herds, $7 \%$ introduced only 1 or 2 males for reproduction. These males are generally carefully tested for infectious diseases before introduction and can be considered as not being animals at risk of introducing pathogens in a destination. Hence, these herds could be grouped with closed herds. A third of the herds were open source herds. Among open source herds, quite a few herds had both numerous introductions coming from several source herds (especially herds with a fattening unit) and numerous destination herds, e.g. at least 180 herds-year had both more than 10 source herds and more than 10 destination herds. Concerning the between-herd propagation of pathogens transmitted by direct contacts, these herds can be considered as super-spreaders. Because a large proportion of the introduced animals in the analysed data is of unknown origin, this number is the minimum number of herds that can play a role of super-spreaders. When considering animal movements instead of between-herd contact, herds that both transferred and introduced more than 30 animals represented $1.3 \%$ of the whole population of herds, i.e. 640 herds-year.

The network between herds due to animal movements was very dense and com- plex. Most of the pairs between a source and a destination herd concerned only one animal. Hence, open herds had almost as many source herds as introduced animals and on average source herds are numerous per destination herd. Each source herd generally had several destination herds and more than $90 \%$ of the pairs between a source and a destination herd lasted for only one year. All this may increase the risk of disease transmission in the area by increasing the probability that any destination herd has at least one infected source herd.

Source herds were mostly of dairy type, which transferred lots of animals to other herds, especially the so-called 8-day calves. Whenever these herds were closed source herds, they can have an epidemiological status at risk due to the potential persistence of pathogens in a closed population or infection by another route (environment or reservoir species for example). Open source dairy herds may highly participate in the between-herds spread of pathogens, especially if those transferring animals to a high number of other herds.

On average, only 2 animals were transferred from or introduced into small herds ('s') per year. However, these herds are very numerous in Brittany and they are related to all the other types of herds in terms of introductions and transfers. Moreover, they are less aware of farm advice and extension services. Even though small herds were implied in only $2 \%$ of the introductions and transfers, they represented $18 \%$ of the destination herds and $8 \%$ of the source herds. As a result, small herds may play a role in the between-herds spread of pathogens.

Heifer herds (specialised in raising dairy females for reproduction) are not very numerous in Brittany. However, more than $80 \%$ of these herds (i.e. around 20 herds per year) both introduced and exported dairy females. Since each open source heifer herd had on average 8 source 
herds and 5 destination herds, they may possibly play a role of a super-spreader for diseases for which adult cattle may be infectious. However, this role may be negligible compared to all the movement between cattle herds in Brittany because heifer herds represented only $0.1 \%$ of the destination herds and $0.1 \%$ of the source herds.

\subsection{Risk of between-herd pathogen propagation due to animal movements}

Animal movements are encountered in highly variable quantities between almost all herd types, and concern all animal types. The herds that are at high risk of being infected by the introduction of an infected animal cannot be readily identified. In particular, the susceptible animals and the infectious animals are not the same for all the pathogens. For instance, concerning the infection by Mycobacterium avium subsp. paratuberculosis, the susceptible animals are mainly calves, whereas the infectious ones are generally adult cattle [6]. Concerning the Bovine Viral Diarrhoea virus, the proportion of persistently infected animals (shedding a high quantity of virus) is higher in young calves, due to mortality consecutive to infection. However, pregnant females are at risk of carrying a persistently infected foetus [8]. As a result, different herd types will be at risk of spreading or being infected by the disease, depending on the pathogen implicated. Moreover, the structure and management of the herd, i.e. the herd type, influence the within-herd pathogen transmission once the pathogen has been introduced $[13,14]$. This within-herd prevalence may also sharply vary over time as the herd infection progresses. A more detailed analysis is needed to study the impact of the between-herd contact structure on the spread of pathogens, taking into account the dynamics of herd- and animal- level prevalences for a given pathogen in addition to cattle movements.

More than half the introduced cattle came from outside Brittany. Management of the animal movements between herds may change over time and between livestock areas, because of movement restrictions for example. In case of a major infectious disease outbreak, the between-herd contact structure (i.e. number of source herds and their health status) may be monitored, in order to reduce the risk of introducing infected animals in a herd at low risk of already being infected. The relationships between livestock areas with different monitoring systems will then be of importance. The epidemiological risk concerning a given pathogen may increase for the introducing livestock area (Brittany here) if the herd- or animal-level prevalences are higher in the source area and if the introduced animals are at risk of being infected.

The results presented here can be used to evaluate the risk of introduction of a particular pathogen in a herd, related to the type of animals at risk. In particular, between-herd animal movements data can be used to parameterise mathematical models of between-herd spread of infectious diseases.

\section{CONCLUSION}

In Brittany, large dairy herds and small herds were the two main herd types. More than half the herds had no fattening unit. A third of the herds were open source herds and $16 \%$ were isolated herds. Half the introduced animals came from outside of Brittany. Open herds had almost as many source herds as yearly introduced animals. More than $90 \%$ of the pairs between two herds in a given year were not renewed the next year. Source herds can be of any type for almost all the types of destination herds. In order to manage animal movements, all herd types should be 
taken into account, even small herds. To control the spread of pathogens betweenherd, herd testing and animal movements, control may be effective if the test is able to detect a high proportion of infected herds.

\section{ACKNOWLEDGEMENTS}

The authors are grateful to the "Centre de Traitement de l'Information Génétique" (CTIG) and the "Union Bretonne des Groupements de Défense Sanitaire" (UBGDS) for making the data available. They would like to thank the two referees for their very useful suggestions.

\section{REFERENCES}

[1] Agreste - GraphAgri, L'agriculture, la forêt et les industries agroalimentaires, La Statistique Agricole, 2004.

[2] Agreste recensement agricole 2000, L'essentiel - France métropolitaine par région, 2001.

[3] Alban L., Stryhn H., Kjeldsen A.M., Ersbøll A.K., Skjoth F., Christensen J., Bitsch V., Chriel M., Stroger U., Estimating transfer of bovine virus-diarrhoea virus in Danish cattle by use of register data, Prev. Vet. Med. 52 (2001) 133-46.

[4] Barlow N.D., Kean J.M., Caldwell N.P., Ryan T.J., Modelling the regional dynamics and management of bovine tuberculosis in New Zealand cattle herds, Prev. Vet. Med. 36 (1998) 25-38.

[5] Christley R.M., French N.P., Small-world topology of UK racing: the potential for rapid spread of infectious agents, Equine Vet. J. 35 (2003) 586-589.

[6] Collins M.T., Paratuberculosis: review of present knowledge, Acta Vet. Scand. 44 (2003) 217-221.
[7] Corn J.L., Nettles V.F., Disinfection and wildlife, Rev. Sci. Tech. OIE 14 (1995) 455468.

[8] Houe H., Epidemiological features and economical importance of bovine virus diarrhoea virus (BVDV) infections, Vet. Microbiol. 64 (1999) 89-107.

[9] Mahul O., Durand B., Simulated economic consequences of foot-and-mouth disease epidemics and their public control in France, Prev. Vet. Med. 47 (2000) 23-38.

[10] Nielsen L.R., Ersbøll A.K., Risk factors for becoming a persistent carrier of Salmonella dublin in infected dairy herds, in: Proceedings of the annual conference of the Society for Veterinary Epidemiology and Preventive Medicine, Martigny, Switzerland, 2004, pp. 111-123.

[11] Sattenspiel L., Population structure and the spread of disease, Hum. Biol. 59 (1987) 411438.

[12] Velthuis A.G.J., The effect of regulations on the contact structure of the Dutch cattle sector, in: Proceedings of the annual conference of the Society for Veterinary Epidemiology and Preventive Medicine, Martigny, Switzerland, 2004, pp. 200-215.

[13] Viet A.F., Fourichon C., Seegers H., Jacob C., Guihenneuc-Jouyaux C., Influence de la structuration du troupeau en lots sur la propagation du virus de la Diarrhée Virale Bovine (BVDV) en élevage bovin laitier, Rev. Méd. Vét. 155 (2004) 132-140.

[14] Viet A.F., Fourichon C., Seegers H., Jacob C., Guihenneuc-Jouyaux C., A model of the spread of the bovine viral-diarrhoea virus within a dairy herd, Prev. Vet. Med. 63 (2004) 211-236.

[15] Weber M.F., van Roermund H.J.W., Assink H.B.J., Stegeman J.A., Rate and structure of cattle transfers between cattle herds considered to be free of paratuberculosis, in: Proceedings of the annual conference of the Society for Veterinary Epidemiology and Preventive Medicine, Martigny, Switzerland, 2004, pp. 216-225. 